\title{
Remy Belleau, Odes d'Anacréon (1573-1574), Amours et Nouveaux Eschanges des Pierres Précieuses, Poésies diverses, Tombeau de Belleau
}

\section{Michele Mastroianni}

\section{(2) OpenEdition \\ Journals}

\section{Edizione digitale}

URL: https://journals.openedition.org/studifrancesi/40512

DOI: $10.4000 /$ studifrancesi. 40512

ISSN: 2421-5856

\section{Editore}

Rosenberg \& Sellier

\section{Edizione cartacea}

Data di pubblicazione: 1 juillet 2004

Paginazione: 174-175

ISSN: 0039-2944

\section{Notizia bibliografica digitale}

Michele Mastroianni, «Remy Belleau, Odes d'Anacréon (1573-1574), Amours et Nouveaux Eschanges des Pierres Précieuses, Poésies diverses, Tombeau de Belleau», Studi Francesi [Online], 142 (XLVIII | I) | 2004, online dal 30 novembre 2015, consultato il 09 septembre 2021. URL: http://journals.openedition.org/ studifrancesi/40512 ; DOI: https://doi.org/10.4000/studifrancesi.40512

Questo documento è stato generato automaticamente il 9 septembre 2021.

\section{cc) $($ ) $\ominus$}

Studi Francesi è distribuita con Licenza Creative Commons Attribuzione - Non commerciale - Non opere derivate 4.0 Internazionale. 


\title{
Remy Belleau, Odes d'Anacréon (1573-1574), Amours et Nouveaux Eschanges des Pierres Précieuses, Poésies diverses, Tombeau de Belleau
}

\author{
Michele Mastroianni
}

\section{NOTIZIA}

REMY BELLEAU, Odes d'Anacréon (1573-1574), Amours et Nouveaux Eschanges des Pierres

Précieuses, Poésies diverses, Tombeau de Belleau, édition critique par Jean BRAYBRoOK, Guy DEMERSON et Maurice-F. VERDIER (Euvres poètiques, sous la direction de Guy DEMERSON: tome V), Paris, Champion, 2003, pp. 480.

1 Volge al termine l'ottima edizione critica dell'opera omnia di Belleau diretta da Guy Demerson. In questo quinto volume sono raccolti gli ultimi testi pubblicati da Belleau ancor vivo, tra il 1573 e il 1577. Abbiamo anzitutto, a cura di Guy Demerson, alcune pièces liminaires per opera di Ronsard, Garnier e Helvis (pp. 15-219). Seguono le composizioni aggiunte da Belleau nella terza edizione (1573?) e nella quarta (1574) delle sue Odes d'Anacréon et Petites Inventions (pp. 23-85). Guy Demerson fa alcune considerazioni di carattere filologico, disegnando le famiglie cui appartengono le varie edizioni del corpus; Maurice-F. Verdier inquadra le nouvelles pièces nel milieu letterario e ne evidenzia l'interesse, distinguendo le poesie erotiche dalle nuove Petites Inventions. La sezione più corposa del volume consiste nell'edizione, introduzione e commento, a cura di Jean Braybrook, della silloge pubblicata nel 1576, che comprende Les Amours et Nouveaux Eschanges des Pierres Precieuses, il Discours de la Vanité, pris de l'Ecclesiaste, le Eclogues sacrées, prises du Cantique des Cantiques (pp. 87-300). Nella sua ampia introduzione, Braybrook analizza l'originalità e la potenza mitografica delle Pierres Precieuses ripercorrendone le fonti in testi scientifici e poetici dall'antichità classica al 
Medioevo al Rinascimento. Così pure, sempre Braybrook, studia gli altri due testi, esercizi esemplari di poesia biblica tra la parafrasi e la rivisitazione originale. Per quanto concerne il Discours de la Vanité, parafrasi dell'Ecclesiaste, esso rappresenta in certo qual modo un revers moral delle Pierres Precieuses: là dove infatti le liriche delle Pierres erano trattazione di gioielli e minerali preziosi che per i contemporanei del poeta erano segno di ricchezza e prestigio, il Discours svolge il topos della vanità della bellezza fisica e della magnificenza della vita umana in genere, secondo la tipologia tipicamente manieriste e barocca delle vanitates. Anche la parafrasi in églogues sacrées del Cantico del Cantici, come quella di Qohelet, si inserisce in una nutrita serie di rifacimenti cinquecenteschi (cfr. M. ENGAMmARE, Le Cantique des Cantiques, Genève, Droz, 1993) e, a monte, in una lunga filière di commenti spirituali e mistici, da cui Belleau riprende l'applicazione allegorica alla Chiesa («L'Eglise divinement esprise d'amour spirituel, souhaitte jouir de la presence de Jesus-Christ, etc.», p. 271). Tuttavia, come Braybrook sottolinea accuratamente, questa parafrasi biblica, ben più della precedente, va messa in rapporto con la precedente creazione poetica di Belleau. È vero che questi «ha scelto un testo che porta alla riflessione religiosa. A livello retorico, l'enumeratio che si incontra in numerosi passi del Cantico è segno linguistico della meditazione, come nelle litanie. A livello tematico, il giardino e l'insieme dei fiori erano simboli tradizionali della contemplazione, come già suggeriva il commento di Alano di Lilla, Elucidatio in Cantica canticorum», ma è anche vero che «il motivo del giardino - e della floraison - è egualmente importante nel contesto laico della Bergerie, ove Belleau descrive il limitare del Château du Grand Jardin a Joinville e celebra il potere che hanno i ritmi della natura di guarire l'uomo malato o turbato dalla guerra: anche là, il giardino ha un significato quasi religioso, paradisiaco. Traducendo un testo organizzato intorno alla nozione di giardino, Belleau vuole senza dubbio spingere i suoi contemporanei almeno a una presa di coscienza della loro situazione disperata» (pp. 264-265). Ultima opera pubblicata nel volume, a cura di Maurice-F. Verdier, è il Tumulus poetico costituito in memoria di Belleau nel 1577 (pp. 301-318: contiene testi in latino, in greco e in francese). Completano il volume dense note (pp. 323-438) che contengono varianti testuali e commento, e un accurato glossario (pp. 439-471). 